\title{
Analysis on the Income Risk and Insurance Pricing of Peanut Planting Farmers in North China
}

\author{
Xiao $\mathrm{Su}^{1} \quad$ Chengyi $\mathrm{Pu}^{1, *}$ \\ ${ }^{1}$ School of Insurance, Central University of Finance and Economics \\ *Corresponding author: Chengyi Pu. Email: pucy@cufe.edu.cn
}

\begin{abstract}
Agricultural production has been affected by natural disasters for a long time. In recent years, extreme meteorological disasters occur frequently in the context of global climate change, causing fluctuations in crop yields and prices, and posing serious threat to rural economic development. Shandong province is a great peanut province. Affected by natural risks such as meteorological disasters and consequent price risks, peanut production is faced with double threats of output and price. However, the current policy-based peanut insurance is difficult to fully disperse the risks and ensure the stability of peanut production. According to the analysis of peanut income risk and pricing mechanism of peanut income insurance, as well as the construction of Copula model based on data from 1991 to 2017, this paper calculates the premium rate of peanut income insurance in Shandong province and four cities. The results show that the pure premium rate is between $1.5 \%$ and $4.15 \%$ under the guarantee level of $70 \%$ to $90 \%$. Compared with the current cost insurance with flat rate of $4 \%$, the income insurance premium rate is generally lower, which can provide more comprehensive protection at lower cost under the same level of protection. This shows that it is feasible to carry out peanut income insurance in Shandong province, which is of great significance to disperse peanut production and operation risks, ensure stable income of planting farmers, promote the solution of problems concerning agriculture, rural areas and farmers, and promote the integrated development of urban and rural areas.
\end{abstract}

Keywords: Meteorological hazard risk, Peanut income insurance, Premium rating, Copula method

\section{华北山地农户花生种植风险与收入保险定价分析}

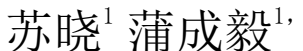

\author{
${ }^{1}$ 中央财经大学保险学院 \\ *通讯作者. 电子邮箱: pucy@cufe.edu.cn
}

\begin{abstract}
摘要
全球气候变化下极端性天气灾难的频发, 农业生产受到巨大影响，引发农作物产量及价格波动，影响种植农户 收入增加，阻碍农村经济发展，对农村经济发展带来严重威胁。华北典型山地山东是花生种植大省，受气象灾 害风险以及随之产生的价格风险的影响，山东省花生农户面临产量和价格的双重威胁。但是，现行政策性花生 保险难以充分的分散风险, 保障生产稳定。本文选择山东花生种植农户为例, 通过对山东省花生收入风险及收 入保险定价机理分析，基于 1991-2017 年数据构建 Copula 模型，对花生收入保险进行费率测算。分析结果表 明: 在 70\%-90\%的保障水平下，纯费率水平介于 1.5\%-4.15\%之间; 与山东省现行的统一费率为 $4 \%$ 的成本保险 相比，收入保险费率总体低于现行费率，在同一保障水平下能够以更低的成本提供更为全面的保障。这表明， 山东省开展花生收入保险具有可行性, 对于分散花生生产经营风险, 保障种植农户收入稳定, 促进乡村经济振 兴, 推动城乡融合发展等具有重要意义。
\end{abstract}

关键词: 气象灾害风险, 花生种植收入保险, 费率厘定, Copula 方法 


\section{1. 引言}

花生是山东省主要的油料作物, 花生收入是山东 省农民增收的重要渠道。近 20 年来, 山东花生播种 面积和总产量与油料作物占比均达到 $96 \%$ 以上。然而, 长期以来自然灾害风险的客观存在和不断加剧, 以及 随之引发的农产品市场价格波动, 成为花生生产稳定 和进一步发展的制约因素。据统计, 2018 年山东省成 灾面积 57.5 万公顷且近年呈扩大趋势, 花生生产价 格指数波动较为剧烈, 山东省花生生产面临产量和价 格的双重威胁。

农业保险是分散种植风险、稳定农业生产的重要 手段。然而, 花生保险在山东省发展相对较晚, 其风 险保障作用客观上也存在一定局限。2006 年, 山东省 开始进行政策性农业保险试点。2014 年, 山东省花生 保险才被列入享受中央财政补贴的农作物品种之一。 目前山东省花生保险险种仍以价格保险为主, 一般只 能保障农户花生种植物化成本的一定比例, 不能充分 满足农户的多样化风险保障需求。2018 年, 山东省对 花生种植保险条款进行修订, 并在全省范围内加以实 施。与修订前相比, 花生平均每亩保险金额由 400 元 提高至 600 元, 每亩保费也由先前的 16 元增加至 24 元。花生保险金额的提升使得花生保险的保障效果得 以增强, 但在日益增加的物化成本和人力成本以及不 断扩大的自然灾害风险的影响下, 这一促进效果十分 有限。且一直以来，山东省花生保险实行 $4 \%$ 的统一 费率, 长期不变的非弹性费率难以与花生产业发展及 农村经济发展步调有效衔接, 花生生产的地域性差异 也难以得到有效体现。在花生生产自然和社会条件不 断变化的同时, 探索创新能够提供更为全面风险保障 的农业保险险种显得尤为必要。

农业收入保险是一类在美国发展较为完善的农 业保险险种，综合考虑了农产品生产和销售过程中的 两大主要风险, 在作物歉收年份提供经济补偿, 同时 防范农产品市场价格变动, 以保障农户收入基本稳定。 美国是较早开展花生收入保险的国家。根据美国农业 部有关报告, 以收入保险（Revenue Protection）为主 的相对完备的花生保险体系在各州已经基本建立，能 够为农户提供全面的保险保障, 包括极端天气、病虫 害、火灾等一般风险、价格变动等市场风险, 地震、 风⿺ 风等巨灾风险也在保障范畴之内。因此, 在山东省
花生自然和社会风险日益严重的趋势下, 分析花生收 入风险以及收入保险定价机理, 首先, 有利于化解农 业生产和经营风险, 稳定农业生产积极性和农业投资 者信心，保障油料供给安全; 其次，有利于促进政府 对三农问题的有效治理，缓解因灾致贫和因灾返贫， 助推脱贫攻坚及精准扶贫有效机制的形成 (邵全泉等, 2017; 张伟等，2020）；最后，有利于抑制城乡市场 割裂的风险, 推动城乡融合发展, 实现农村振兴、农 业现代化以及经济社会发展（江生忠等，2018；度国 柱，2019）。

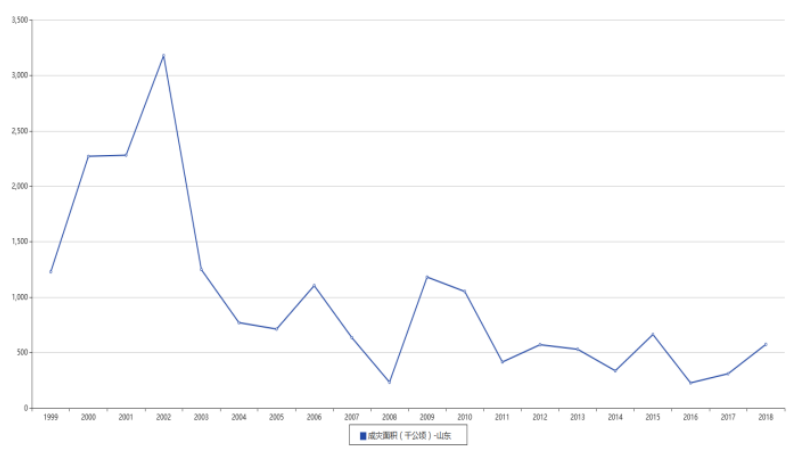

图 1 1999-2018 年山东省成灾面积

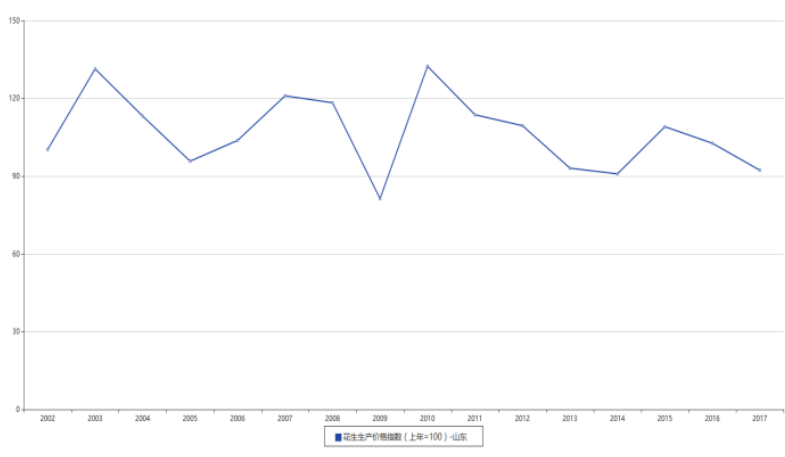

图 2 2002-2018 年山东省花生生产价格指数

\section{2. 文献综述}

\section{1 收入保险发展研究}

国外较早开展收入保险试点, 美国的 Crop Revenue Coverage (CRC) 是最早的收入保险形式。 国外对收入保险发展及作用效果等的研究也较为丰 富。Bruce（1997）将收入保险计划与 1990 年的农业 保险计划进行比较发现，收入保险具有更高的再分配 效率, 且能够以更低的成本为农户提供基本相同的收 益水平。XU (2014) 将保险机制引入基础经济增长模 型发现, 收入保险和保费补贴对促进农作物产出和农 业经济增长具有显著的正向作用。 
国内收入保险尚未进入试点阶段。国内学者的研 究重点主要从宏观层面对收入保险展开定性分析。肖 宇谷和王克 (2013) 指出农业收入保险的开展具有重 要的实践意义, 并从收入保险成功的三要素入手论证 了我国开展收入保险的可行性。开展农业收入保险, 有利于弥补市场上现有险种风险补偿能力不足的局 限, 为农业生产提供充分的保险保障，加快农业保险 险种策略创新, 最终助推农业供给侧结构性改革（曾 勤，2016）。度国柱、朱俊生（2016）通过市场风险 特征分析指出价格指数保险的局限性, 并结合美国农 业收入保险发展，提出发展收入保险对我国农产品价 格形成机制改革具有重要作用。农业收入保险的经济 效益随着保障水平的增加而提升, 开展收入保险不仅 能够降低保险费率，保险需求、保费收入、保险深度 和保险密度也将实现不同程度的改善 (王保玲等, 2017）。林乐芬、李远孝（2020）通过江苏省县级经 验数据分析得出, 风险因素和经营特征对农户收入保 险响应意愿具有显著影响, 随着受灾次数的上升和农 产品价格的下跌, 农户参加收入保险的意愿愈加强烈。

\section{2 收入保险定价研究}

收入保险定价的核心是单产和价格边缘以及联 合分布拟合。国内外在费率测算的主流方法方面基本 保持一致。

在单产和价格的分布拟合问题上, 参数法和非参 数法是两种主要方法。参数法操作简单, 拟合产量数 据常用的分布有 Beta 分布 (Grant, 1989)、Log-normal 分布 (Goodwin, 2000)、Weibull 分布 (Lanoue, 2010) 等; 拟合价格数据常用的分布有 Burr 分布 (Tejeda, 2008)、Log-logistic 分布 (Ghosh, 2008)、Log-normal 分布 (Goodwin, 2000) 等。但由于参数法分布先验, 具有一定的随机性和主观性, 在风险度量上存在可能 存在偏差。非参数法能够很好的弥补上述不足, 通过 引入核函数, 选择合适的窗宽确定最优分布, 进而提 高对产量及价格风险追踪的精确程度 (Borman, 2013)。

在产量和价格的关系问题上, CRC 以二者相互 独立为基本假定（谢风杰, 2011）。但实际上, 产量 和价格非独立, 并根据具体情形或呈正相关, 或呈负 相关, 相关程度也存在一定差异。因此, 后续相关研 究多使用 Copula 方法对二者间的相关关系进行刻画

(Ghosh, 2008; Woodard, 2011; Ahmed, 2015; Tejeda, 2015）。国内对收入保险进行定价研究也大多采用
Copula 方法。研究区别主要在于作物种类、数据选择、 边缘分布以及 Copula 函数形式。谢风杰等 (2011) 以 安徽省阜阳市为研究对象, 选取玉米、小麦和大豆三 种代表性作物，最早使用 Copula 方法对收入保险定 价问题进行了研究。冯文丽等(2017)、田菁等(2019) 也先后以粮食作物为例, 基于 Copula 方法对收入保 险费率进行了厘定。徐婷婷等 (2017) 运用 Copula 方 法对山西苹果收入保险进行了定价研究。具体到花生 作物，杨馥、仲璇（2019）和郭以馨（2019）先后使 用 Copula 方法对河南省花生收入保险进行了定价研 究。后者在前者的基础上对省内区域化差异加以考虑, 并就特定产区设计了天气指数型收入保险, 二者最终 计算得出的费率也有较大差异。但总体而言, 目前国 内对花生收入保险的定价问题关注仍有一定欠缺。

\section{3. 花生收入风险分析及收入保险定价机理}

\section{1 花生单产的影响因素分析}

农户是劳动生产的最小单位, 在花生种植过程中, 农户通过投入劳动、资本、技术等要素获得产出, 花 生投入与产出的关系可以用以下柯布道格拉斯生产 函数表示:

$$
Q_{t}=A\left(K_{1}+K_{2}\right)^{\alpha} L^{\beta}
$$

其中: 设定技术投入 $\mathrm{A}$ 与劳动投入 $\mathrm{L}$ 既定; 资 本投入 $\mathrm{K}$ 可分为保费 $\mathrm{K} 1$ (包括财产损失保险即产量 损失保险、人员健康意外保险）和除保费投入外的其 他资本投入 $\mathrm{K} 2$ 。

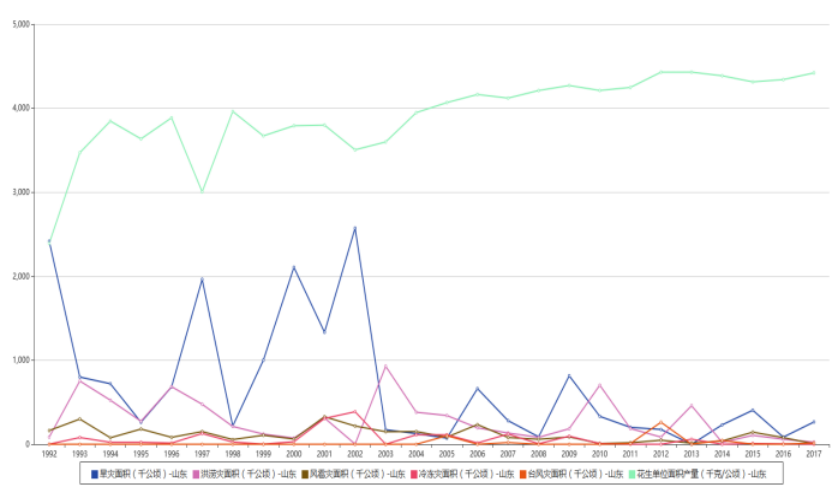

图 3 山东花生单产与气象灾害成灾面积

除要素投入外, 花生产量还受多种因素的影响。 其中, 气象灾害对山东省花生单产影响较大, 尤其是 旱灾。尽管花生是耐干旱作物, 但其在发芽开花期 (一 
般为 5-6 月份) 对水分需求较为旺盛, 而山东省 $60 \%$ $80 \%$ 的降水集中在夏季，春夏之交降水相对不足，难 以满足花生发芽开花必要的水分条件。图 3 表明, 山 东省花生单产与旱灾成灾面积具有较为明显的负相 关关系，而与洪涝灾害成灾面积则不具有明显的相关 性。

\section{2 花生价格的蛛网理论模型分析}

花生是山东省主要的油料作物, 花生生产供给与 需求之间存在时间差, 花生种植农户的产量受上一期 价格的影响, 而花生加工企业的需求量受当期价格的 影响。显然, 花生的供给和需求决策符合蛛网理论模 型假定。本文分别选取山东省 1991-2017 年花生产量 和平均出售价格指标，建立蛛网理论模型：

$$
\left\{\begin{array}{l}
Q_{\mathrm{d}}=3044+216.72 P_{\mathrm{t}} \\
Q_{\mathrm{s}}=3035.5+226.96 P_{\mathrm{t}-1} \\
Q_{\mathrm{d}}=Q_{\mathrm{s}}
\end{array}\right.
$$

$226.96 / 216.72=1.0472>1$, 此为发散型蛛网模型, 即随着时间 $\mathrm{t}$ 的推移, 花生的实际价格将以越来越大 的幅度围绕均衡价格上下波动, 最后无限偏离均衡价 格。花生价格的大幅波动将会对种植农户收入和相关 企业生产的稳定性产生严重冲击。

\section{3 收入缺口与费率测算}

设定历年收入的均值 $y$ 为无风险状态下的期望 收入, $y_{t}$ 为历年收入, 则 $\Delta y_{t}=y_{t}-\hat{y}_{\text {为风险状态下 }}$ 的收入缺口。

当收入缺口为负时，触发收入保险赔付机制，农 户获得赔偿，保险金额为期望收入与当年实际收入的 差额。据此可得农户获偿金额:

$$
\operatorname{Pension}(y)=\left\{\begin{array}{c}
\hat{y}-y_{t}, \Delta y_{t}<0 \\
0, \Delta y_{t}>0
\end{array}\right.
$$

设定 $\alpha$ 为保险保障水平,一般地, $\alpha \in[0.7,0.9]$ 。 根据以下公式计算保险纯费率:

$\operatorname{ExpectedLoss}(y)=\operatorname{prob}(y<\alpha \hat{y})[\alpha \hat{y}-E(y \mid y<\alpha \hat{y})]$

$r=\frac{\text { ExpectedLoss }}{\alpha \hat{y}}$

\section{4. 花生收入保险费率测算}

\section{1 数据选取与处理}

本文首先选取 1991-2017 年山东省花生年度单产 和价格数据, 进行收入保险费率测度。考虑到花生生 产的区域性差异，选取青岛市、烟台市、临沂市和菏 泽市的花生年度产量及价格数据, 分别进行费率厘定。 产量选取花生单产指标, 数据来源为历年《山东统计 年鉴》; 价格选取每 50 千克主产品平均出售价格指 标, 数据来源为《全国农产品成本收益资料汇编》。

时间序列数据具有趋势性特点, 可能影响分布拟 合及最终结果的可靠性, 因此对数据进行单位根检验。 表 1 结果表明烟台市、菏泽市的单产和价格序列非平 稳。为了得到平稳时间序列，本文使用 H-P 滤波方法 对数据进行去趋势化处理。设定显著性水平为 0.05 , 处理后的花生单产和价格序列平稳。为了消除量纲对 结果的影响, 对数据进行标准化处理。

表 1 单位根检验与去趋势结果

\begin{tabular}{ccccc}
\hline \multirow{2}{*}{ 指标 } & \multicolumn{2}{c}{ 处理前 } & \multicolumn{2}{c}{ 处理后 } \\
& p-value & 检验结果 & p-value & 检验结果 \\
\hline 山东省 & 0.0012 & 平稳 & & 平稳 \\
青岛市 & 0.0056 & 平稳 & & 平稳 \\
产量 烟台市 & 0.1113 & 不平稳 & 0.0189 & 平稳 \\
临沂市 & 0.0473 & 平稳 & & 平稳 \\
菏泽市 & 0.0871 & 不平稳 & 0.0101 & 平稳 \\
价格 & 0.1619 & 不平稳 & 0.0251 & 平稳 \\
\hline
\end{tabular}

\section{2 单产和价格分布拟合}

选取常见分布形式 Burr、Gamma、Normal、 Logistic、Log-Logistic、Log-Normal、Weibull，使用 Python 2.7 分别对山东省以及青岛、烟台、临沂、菏 泽四市的单产和价格数据进行边缘分布拟合, 输出对 应的 AIC、BIC 值, 并根据平方和误差最小的原则选 择最优分布。单产和价格分布拟合的具体结果如表 2 所示。

\begin{tabular}{|c|c|c|c|}
\hline \multicolumn{2}{|l|}{ 指标 } & 分布 & 参数 \\
\hline \multirow{5}{*}{ 产量 } & 山东省 & Logistic & $\begin{array}{l}\mu=0.1126 \\
\sigma=0.6468\end{array}$ \\
\hline & 青岛市 & Logistic & $\begin{array}{l}\mu=0.1053, \\
\sigma=0.7353\end{array}$ \\
\hline & 烟台市 & Logistic & $\mu=0.112, \sigma=0.6373$ \\
\hline & 临沂市 & Logistic & $\begin{array}{l}\mu=0.1253 \\
\sigma=0.7652\end{array}$ \\
\hline & 菏泽市 & Logistic & $\mu=0.1077, \sigma=0.6309$ \\
\hline 价格 & & Normal & $\begin{array}{l}\mu=0.4841 \\
\sigma=0.2780\end{array}$ \\
\hline
\end{tabular}

表 2 单产及价格边缘分布拟合结果 


\section{3 单产和价格联合分布拟合}

选取常用 Copula 函数 Gaussian、t、Clayton、Frank、 Gumbel Copula, 使用 R Studio 软件进行联合分布拟 合，具体结果如表 3 所示。

表 3 单产及价格联合分布拟合结果

\begin{tabular}{lccl}
\hline 地区 & Kendall 系数 & Copula 函数 & 参数 \\
\hline 山东省 & 0.0631 & Clayton & 0.11 \\
青岛市 & -0.0742 & Gumbel & -1.17 \\
烟台市 & 0.1198 & Frank & 1.01 \\
临沂市 & 0.1655 & Gumbel & 1.29 \\
菏泽市 & -0.0285 & Gumbel & -1.11 \\
\hline
\end{tabular}

\section{4 蒙特卡洛模拟与费率计算}

通过蒙特卡洛方法生成 10000 组单产和价格的 随机序列。设定 70\%-90\%保障水平下的收入保险纯 费率计算结果如表 4 所示。

表 4 收入保险纯费率结果及与现行成本保险比较

\begin{tabular}{cccccc}
\hline 地区 & $70 \%$ & $75 \%$ & $80 \%$ & $85 \%$ & $90 \%$ \\
\hline 山东省 & $1.5 \%$ & $2.22 \%$ & $2.93 \%$ & $3.69 \%$ & $4.15 \%$ \\
青岛市 & $0.85 \%$ & $1.67 \%$ & $2.21 \%$ & $2.95 \%$ & $3.47 \%$ \\
烟台市 & $1.91 \%$ & $2.29 \%$ & $3.32 \%$ & $3.85 \%$ & $4.33 \%$ \\
临沂市 & $2.01 \%$ & $2.78 \%$ & $3.59 \%$ & $3.98 \%$ & $4.54 \%$ \\
菏泽市 & $0.98 \%$ & $1.88 \%$ & $2.71 \%$ & $3.21 \%$ & $3.86 \%$ \\
成本险 & $4 \%$ & $4 \%$ & $4 \%$ & $4 \%$ & $4 \%$ \\
\hline
\end{tabular}

\section{5. 结论与建议}

通过山东省及四市 1991-2017 年的单产和价格数 据，使用 H-P 滤波方法、Copul 方法、蒙特卡洛方法 等进行收入保险纯费率测算发现, 在 70\%-90\%的保 障水平下, 纯费率水平介于 $1.5 \%-4.15 \%$ 之间。相比较 而言, 青岛市和菏泽市的费率水平总体较低, 这可能 是因为二者 Kendall 秩相关系数为负, 即单产和价格 存在弱负相关关系, 产量风险和价格风险具有一定的 对冲效应。同时, 与山东省现行的统一费率为 $4 \%$ 的 成本保险相比, 收入保险总体费率低于现行费率, 在 同一保障水平下能够以更低的成本提供更为全面的 保障。因此, 花生收入保险的开展具有其可行性。

但在较高的保障水平上, 收入保险的费率水平仍 然相对较高, 尤其是在单产和价格对冲效应不显著的 情况下, 这表明, 收入保险的开展离不开政府保费补 贴等政策的扶持, 建立完善 “农户-专业合作社-相关 企业-政府” 多主体、多渠道的保费分摊模式, 创新农 业保险保费补贴机制, 实现农业生产与农业保险发展 良性互动。

\section{致谢}

本文是北京高校高精尖学科“战略经济与军民融 合”交叉学科（GJJ2019163）、中央财经大学“一流学 科”建设项目“巨灾风险管理与自然灾害治理现代化 研究”, 2020 年度国家民委民族研究项目“后脱贫时代 西部藏区乡村振兴风险与内置金融研究 (2020-GMB030）”的阶段性研究成果。

\section{参考文献}

[1] 林乐芬,李远孝.风险因素、经营特征对规模农户水稻收 入保险响应意愿的影响——基于江苏省 33 个县的经 验证据[J].保险研究,2020(05):50-65.

[2] 田菁,张琅, 袁佳子.农作物收入保险省及地级市定价研 究——辽宁省玉米、大豆为例 [J]. 保险研 究,2019(03):103-115.

[3]王保玲,孙健,江崇光.我国引入农业收入保险的经济效 应[J].保险研究,2017(03):71-89.

[4] 度国柱,朱俊生.论收入保险对完善农产品价格形成机 制改革的重要性[J].保险研究,2016(06):3-11.

[5] 肖宇谷,王克. 中国开展农作物收入保险的意义和可行 性初探[J].农业展望,2013,9(10):29-32.

[6] 谢风杰,王尔大,朱阳.基于 Copula 方法的作物收入保险 定价研究——安徽省阜阳市为例 [J]. 农业技术经 济,2011(04):41-49.

[7] 周建涛, 于然. 我国农业保险应以经济作物收入保险为 切入点[J].农业经济,2005(01):56-57.

[8] Goodwin B K and Hungerford A. Based Models of Systematic Risk in U.S. Agriculture: Implications for Crop Insurance and Reinsurance Contracts [J]. American Journal of Agricultural Economics, 2015, 97(3), 879-896.

[9] Ghosh S, Woodard J D and Vedenow D V. Efficient Estimation of Copula Mixture Model: An Application to the Rating of Crop Revenue Insurance [J]. Agricultural and Applied Economics, 2011, 33(8), 55-69.

[10] Tejeda H A and Goodwin B K. Modeling Crop prices through a Burr distribution and Analysis of Correlation between Crop Prices and Yield using a Copula method [J]. American Agricultural Economics Association, 2008, 18(3), 85-95.

[11] David A. Hennessy, Bruce A. Babcock, Dermot J. Hayes. Budgetary and Producer Welfare Effects of Revenue Insurance $[\mathrm{J}]$. American Journal of Agricultural Economics, 1997, 79(3), 85-99.

[12] Grant. Two conditional Beta distribution as a stochastic production function [J]. American Journal of Agricultural Economics, 1989, 71(4), 1045-1045. 